humanidades em diálogo, v. 10 (2021)

https://doi.org/10.11606/issn.1982-7547.hd.2021.158741

\title{
AS RAÍZES WEBERIANAS DE UMA INTERPRETAÇÃO DO BRASIL
}

\author{
MARCELO VAZ DE OLIVEIRA JÚNIOR ${ }^{1}$
}

\begin{abstract}
Resumo: Sérgio Buarque de Holanda, ao retornar da Alemanha, na década de 1930, dedicou-se a um trabalho de interpretação sociológica acerca da realidade brasileira com base na metodologia weberiana, realizando um trabalho original. Para além dos tipos ideais, Holanda utilizou ideias contidas nas análises substantivas de Max Weber, como nos estudos sobre a ética protestante e sobre o processo de racionalização das esferas sociais, bem como do aporte histórico-comparativo e de análise em múltiplos níveis, os quais serão explorados no decorrer deste artigo.
\end{abstract}

Palavras-chave: Max Weber; Metodologia; Racionalização; Raízes do Brasil; Sérgio Buarque de Holanda.

1

INTRODUÇÃO

A obra Raízes do Brasil, publicada pela primeira vez em 1936, recebendo uma edição substancialmente revisada doze anos depois ${ }^{2}$, inovou na forma como até então o Brasil era interpretado. Essa inovação se deu em meio a um clima intelectual em que preponderavam ideias naturalistas, pautando que fatores naturais e biológicos eram responsáveis por um certo atraso civilizacional do Brasil. Desmistificando tais proposiçôes, Sérgio Buarque de Holanda buscou demonstrar que, na verdade, eram fatores socioculturais os responsáveis pelo modus operandi da sociedade brasileira, realizando uma investigação profunda no sentido de descobrir e expor aquilo que intitula sua obra: as Raizes do Brasil.

Em sua investigação, Holanda utilizou largamente o método histórico-comparativo, uma apropriação daquilo que era corrente nas obras da sociologia alemã com as quais

1 Graduando em Direito na Faculdade de Direito da Universidade de São Paulo.

marcelo_vaz@usp.br

2 Neste sentido, são de grande valia os comentários realizados por Feldman (2013, p. 120), apontando para a existência de alterações em três ordens argumentativas: a variação da postura axiológica perante a tradição, deslocando-se o foco da resiliência da tradição perante o processo de modernização para as condições necessárias para a efetivação deste; a substituição do personalismo pela democracia, no sentido dado à obra pela interpretação de Candido (1982, p. 8; 1984, p. 33); e a reformulação do enunciado do desterro, sendo possível sustentar uma resignação pragmática com a cordialidade, que na nova edição cedeu espaço à civilidade. 
teve contato quando viajou para Berlim. Nesta viagem, realizada entre os anos de 1929 e 1930, Holanda trabalhou como correspondente de um jornal bilíngue destinado a tornar conhecidas as culturas brasileira e alemã reciprocamente (CANDIDO, 1982, p. 5-6). Nela, ele teve contato com o círculo artístico-literário de Stefan Georges, por meio do qual chegou às obras de Werner Sombart e Max Weber, por exemplo.

A apropriação de aportes heurísticos de autores representativos do Georges Kries ${ }^{3}$ pode ser constatada ao se verificar que Holanda faz remissóes a uma larga bibliografia alemã na construção de seu texto, mais evidente na primeira do que nas demais edições. Dentre os autores alemães citados por Holanda se encontra Max Weber, autor este que, com seu método histórico-comparativo, tipológico e compreensivo, e sua potente teoria social, escreveu sobre diversos assuntos. Weber, como Holanda, iniciou sua carreira no âmbito jurídico e terminoua como sociólogo ou, em razão da multiplicidade analítica contida em seus textos, como teórico social.

Há que se salientar que não somente a metodologia weberiana está presente na obra buarquina. Assuntos tratados pelo teórico alemão, como a formação das culturas, a língua, a dominação, a racionalidade e as tendências de seu tempo, aparecem como escopo de Raizes do Brasil, como bem aponta Eugênio (2011, p. 159). Contudo, ao aproximar a obra de Holanda com a de Weber, nota-se que a do primeiro contém alguns elementos que questionam as tendências apontadas pelo segundo. Portanto, longe de ser um discípulo do autor alemão, o brasileiro se apropria de seus aportes heurísticos a fim de explicar os matizes do "atraso" do país (VIANNA, 1999, p. 33-34).

É fato que interpretações contemporâneas tendem a afastar os argumentos como os de Candido (2014, p. 18-20) e Monteiro (1996, p. 11-23) a respeito da apropriação da metodologia weberiana por Holanda. Dentre estas interpretaçóes, podem ser citadas a que aproxima a obra buarquina do estilo de Simmel (Cohn, 2002); a que alinha Holanda a Nietzsche, feita por Waizbort (2011, p. 42-43); outra que o associa a Oswald Spengler, elaborada por Mata (2016, p. 12-13); ou ainda as contidas na edição crítica de Raízes do Brasil publicada em 2016, que vinculam a obra ao contexto histórico-político. Não obstante, ao se comparar a

3 Nome do círculo coordenado por Stefan Georges, ligado diretamente com o movimento da Revolução Conservadora que acontecia na Alemanha daquela época. Este movimento foi caracterizado pela existência de uma geração de intelectuais, no período da República de Weimar, que tinham como referência o irracionalismo filosófico, o antiliberalismo, a crítica dos direitos humanos, a recusa da democracia representativa e a apologia de uma ditadura cesarista, dentre os quais se destacaram Carl Schmitt e Oswald Spengler, sendo a obra de Nietzsche o referencial deste movimento. 
obra dos dois autores, não é possível mitigar os traços weberianos desta interpretação do Brasil.

Tendo em mente estes aspectos, o ensaio seguirá com quatro seções após esta introdução. Na primeira, serão traçadas as principais características da metodologia weberiana, a saber, a forma de análise em múltiplos níveis, o aporte histórico-comparativo e a toada típicoideal, e se mostrará como elas se manifestam na obra de Holanda. Tendo em conta esta exposição metodológica, na segunda seção, tratar-se-á da formação da cultura ibérica e da reverberação de suas características na esfera do trabalho, defrontando isto com o modo utilizado por Weber para demonstrar como a ética protestante influiu, de modo distinto, na mesma esfera.

$\mathrm{Na}$ terceira seção, contrastar-se-á o apontamento weberiano sobre a racionalização da vida com os de Holanda a respeito da predominância das açốes afetivas e tradicionais no Brasil, utilizando-se o tipo ideal do homem cordial para tal, o que também auxiliará a destacar as características utilizadas pelo autor para construí-lo. Por fim, as considerações de Holanda, propostas na segunda edição de Raizes do Brasil sobre uma possível revolução brasileira serão relacionadas com as tendências esboçadas por Weber, evidenciando mais um ponto de apropriação das análises do autor alemão, e se seguirá para a conclusão.

As discussões acerca da metodologia weberiana ainda movimentam pesquisas, constituindo um campo de disputas acadêmicas (SELL, 2016, p. 338-343). É corrente a proposição de que Weber é um autor que se utiliza do individualismo metodológico, tendo em vista sua ênfase na categoria da ação social como célula da sociologia compreensiva. No entanto, é possível notar em seus escritos analíticos a predominância, não de indivíduos, mas de formaçôes socioculturais, sendo possível caracterizá-lo como um individualista nominalista (SELL, 2016, p. 328). Por isso, a metodologia analítica weberiana possui dois traços fundamentais: o bolismo metodológico moderado e a base histórico-comparativa, que recebem subsídio dos tipos ideais.

Considerando que inexistem leis causais no nível macro, o bolismo metodológico moderado, segundo Albert (2016, p. 55-60), parte do argumento da realizabilidade múltipla, ou seja, as causalidades não são necessárias, são, ao contrário, adequadas. Desta forma, ao acei tar efeitos macro, de formações socioculturais, mesmo que sejam fenômenos históricos e não 
leis trans históricas, este método trabalha com três níveis teóricos: consideração dos efeitos do nível macro sobre os agentes sociais, a teoria da ação pluralista e a relação micro-macro.

O primeiro desses níveis se manifesta, por exemplo, quando Weber trata das ordens sociais. Uma ordem pode ser sociologicamente definida como uma força empírica que orienta as ações dos agentes sociais, as quais, por seu turno, mediante orientação recíproca, terceiro nível teórico, colaboram para a construção e elaboração de formações socioculturais, como a própria ordem. Não obstante, no segundo nível teórico, há a possibilidade de os agentes sociais orientarem suas açóes tomando como referência distintas ordens, como a jurídica e a econômica, o que fazem não somente cumprindo, mas transgredindo as máximas das mesmas. No entanto, quando a transgressão se torna uma regra, a ordem deixa de viger, pois só vige quando há a probabilidade de ações orientarem-se por ela.

Com este método, Weber pretendeu compreender o sentido das ações sociais, para o que elaborou tipos ideais. Em seu ensaio Estudos críticos sobre a lógica das Ciências da Cultura, Weber (2016, p. 275-352), ao criticar a metodologia investigativa de Edward Meyer, buscou elucidar determinados recursos heurísticos para a realização da pesquisa sociológica, pautando a imputação de acontecimentos a causas no universo selecionado, o que acontece por meio de categorias definidas em decorrência de determinados elementos. Estes recursos heurísticos possibilitam a passagem de uma causação acidental para uma adequada, tendo em vista a multiplicidade de explicações possíveis.

Assim, Weber defendeu que, por mais que a iniciativa investigativa partisse de um ato subjetivo do pesquisador, tendo em vista que a escolha do objeto é feita por meio de valo res, a estrutura lógica da explicação nas ciências histórico-sociais deveria garantir validade dos resultados. Dessa forma, o rigorismo científico das ciências sociais poderia se utilizar do tipo ideal, recurso heurístico que define um conjunto de categorias construídas pelo pesquisador para a realização de seu trabalho.

Com esta ferramenta, Weber realizou uma série de análises histórico-comparativas. Notável, por exemplo, é sua Sociologia do Direito, o capítulo 7 de Economia e Sociedade, no qual se refere aos tipos de direito predominantes em épocas históricas distintas, comparando os traços das mesmas entre as diversas culturas. Além desta comparação, ele também fez outra, no mesmo capítulo, entre os tipos de pensamento jurídico continental e insular, ou seja, os que vigoravam na Europa continental e na Inglaterra, evidenciando o motivo da predominância de dois sistemas jurídicos diferentes em lugares tão próximos.

Elucidados os traços basilares da metodologia weberiana, passa-se a identificá-los em Raizes do Brasil. O bolismo metodológico é ressaltado quando Holanda trata da cultura ao 
atribuir à coletividade ibérica uma série de traços comuns, como o da cultura da personalida$d e$. Ela se caracteriza como uma formação sociocultural (macro) que, ao ser compartilhada e reforçada pelos agentes sociais (micro), acarretava uma série de problemas na estrutura social do Brasil (macro). Tal formação, calcada em vínculos sentimentais e na valorização de atos pessoais, tornava quase inevitáveis as desigualdades sociais da sociedade, fundamento das relações assimétricas nela ocorrentes (BASTOS, 2016, n. p.).

Há que se ressaltar que tanto na edição de 1936 quanto na de 1948, a cultura da personalidade foi colocada como um obstáculo à democracia no Brasil: na primeira, um impeditivo total, na segunda, um obstáculo a ser superado (FELDEMAN, 2013, p. 125-126). Em razão de manter o tradicionalismo patriarcal, a cultura da personalidade obstruía a manifestação autônoma e consciente de todos os agentes individuais, havendo, portanto, uma incompatibilidade entre estes dois fatores (WAIZBORT, 2011, p. 42).

Quanto aos tipos ideais e o método histórico-comparativo, são notados em sua análise sobre a colonização das Américas Ibérica e Saxã, caracterizando dois tipos de atitude sintetizadas no trabalhador e a do aventureiro. Para Holanda, os ibéricos foram desbravadores dos trópicos, atividade desempenhada com desleixo, como um aventureiro, agente que visa um fim proporcionador de uma vantagem imediata, ignorando os esforços intermediários. Tal tipo se opóe ao do trabalhador, agente que estuda as dificuldades antes de conseguir alcançar o fim almejado, atribuindo valor moral positivo somente àquilo que possui ânimo para praticar.

Outro exemplo de utilização do recurso do tipo ideal é a caracterização do ladrilhador e o semeador, uma dicotomia entre os castelhanos e os portugueses que encaminha para uma abordagem histórico-comparativa dos processos de colonização da América. Estes dois tipos aludem à institucionalização da colonização, feita com método pelos castelhanos, que se preocuparam em realizar um plano urbanístico desde o início; os portugueses, por sua vez, se contentaram com a pulverização desordenada dos povoados, até encontrem ouro em Minas Gerais. Neste momento, é interessante notar que Holanda remete à obra de Weber como referência para contextualizar a importância das cidades para a dominação, o que será tratado em seção posterior.

Além destes traços metodológicos, a presença de Weber em Raizes do Brasil é evidenciada nas remissões diretas de Holanda para realizar análises histórico-comparativas. Quando trata dos Novos Tempos, por exemplo, o autor fez alusão à Ética Protestante e o Espírito do Capitalismo, comparando o fato de a cultura enraizada no Brasil não prezar, a priori, o traba- 
lho como um fim em si mesmo. O valor final estava, sim, na obra dotada de personalidade, o que destoou dos protestantes, para quem o trabalho possuía valor religioso.

Cabe ainda mencionar a questão da racionalidade, que serve como pano de fundo da obra dos dois autores. Para Weber, a racionalidade, que está ligada ao aumento da calculabilidade das açôes, é um fator que está na essência da modernidade, havendo uma tendência para sua generalização: o processo de racionalização da vida e do desencantamento do mundo. Holanda, no entanto, ao trazer argumentos acerca da predominância da ação tradicional e da ação afetiva no Brasil, em razão de suas raizes, faz com que a velocidade do processo descrito por Weber seja colocada em questão. O intérprete brasileiro relaciona este retardamento com o fato de, até mesmo na administração pública, o personalismo e o sentimento familiar serem preponderantes, o que será tratado nas seçóes seguintes.

\section{FORMAÇÃO DO IBERISMO E A ESFERA DO TRABALHO}

Nos termos de Weber (2000, p. 202), a formação de uma tradição está ligada à apropriação monopólica de bens simbólicos e materiais representada por uma convenção. Assim, o comportamento dos agentes sociais é garantido difusamente dentro de um âmbito específico mediante a aprovação ou reprovação social de determinado comportamento. Neste sentido, Holanda (2014, p. 186) afirma que a herança ibérica recebida pelos brasileiros teve seu conteúdo formado por traços peculiares em comparação com a das outras naçóes europeias. Estes traços caracterizam bens "monopolizados" e repassados como "herança” pelo processo de socialização.

Dentre os monopólios da cultura ibérica, encontra-se o culto da personalidade, já tratado brevemente acima, que implicou na dificuldade de formação de relações de solidariedade. Derivou daí a dificuldade de se obedecer, pois isso requer a renúncia de si a favor da submissão aos desígnios de outrem. Na concepção de Holanda, este traço explicaria a instabilidade da estrutura social do Brasil, cujas raízes estão fincadas na cultura ibérica, principalmente na cultura portuguesa, havendo aspectos originais e outros adaptados mais ou menos pelas condiçốes locais.

Além disso, o princípio da hierarquia não importou muito à cultura ibérica, diluindo-se em privilégios, o que Holanda fez questão de ressaltar que não se tratava de um fato intrinsecamente biológico, mas socialmente construído. Isto significa que a burguesia mercantil, em vez de romper com as características tradicionais da sociedade medieval, assimilou seus 
valores, utilizando-os como padrão de conduta em detrimento dos padrões calculistas característicos da sociedade moderna. Portanto, perpetuou-se a tradição, calcada na ética dos fidalgos, na qual o mérito pessoal fundado em determinadas virtudes ganhou uma grande importância, colaborando com o desenvolvimento da cultura da personalidade.

Por isso, os ibéricos não se caracterizavam como um povo afeito à ética do trabalho, pois o trabalho manual implica na realização de um fim exterior à personalidade. Lembrase que os portugueses foram desbravadores dos trópicos, atividade que desempenharam com desleixo. Esta postura pode ser vinculada ao tipo ideal do aventureiro, aquele agente que visa um fim que lhe proporcione uma vantagem imediata, ignorando os esforços intermediários. Tal tipo se opóe ao do trabalbador, agente que estuda as dificuldades antes de conseguir alcançar o fim almejado, atribuindo valor moral positivo somente àquilo que possui ânimo para praticar.

Comparando estes dois tipos, Holanda remeteu à Ética Protestante e o Espirito do Capitalismo de Weber (2013). Nesta obra, Weber traçou uma linha histórica das bases ideológicas do protestantismo e demonstra como a ética religiosa foi capaz, através de uma afinidade eletiva, combinar-se com a ética econômica essencial para o capitalismo. Assim, a remissão de Holanda se justifica em razão de toda a ética puritana, e quiçá protestante, ter se baseado na questão do trabalho, que ensejou uma lógica de empresa racional burguesa e de organização racional do trabalho.

Nesta senda, a divisão do trabalho era considerada virtuosa por fazer com que to dos os agentes desempenhassem seus talentos e se suprissem reciprocamente, aumentando a solidariedade social. No que tange ao lucro, ele era permitido e essencial no trabalho, uma vez que sua função era demonstrar a Deus o fruto das virtudes por ele outorgadas. Além disso, a mudança da profissão, desde que fosse para uma mais útil, era permitida para o aumento da glória de Deus.

Como defendiam que a riqueza deveria ser bem utilizada, não provocando o ócio, os puritanos passaram a poupá-la, engendrando um processo de acumulação de capital. Este tipo de conduta se espalhou entre as religiões protestantes, dando ensejo a uma ética econômica, um ethos profissional especificamente burguês. Se em um primeiro momento este ethos esteve restrito à esfera da religião (WEBER, 2013, p. 205), posteriormente ele migrou para outras esferas sociais mediante uma incorporação utilitarista. A partir daí as graças advenientes do trabalho, o sucesso econômico em si, passaram a ser vistas pelos religiosos como um sinal de salvação por parte de Deus. Para os agentes econômicos, a sistematicidade das condu- 
tas do ethos protestante, como supramencionado, auxiliou na estruturação do capitalismo ocidental.

Na comparação de Holanda, o contrário disto aconteceu com os portugueses, cuja matriz católica estabeleceu que o trabalho manual não deveria ser feito por nobres. Por isso, a priori, os colonizadores submeteram os gentios ao processo de escravização, mas estes não se adaptaram ao trabalho especializado e metódico. Buscou-se, então, importar escravos africanos, tendo em vista as experiências pregressas de Portugal em suas outras colônias do Atlântico.

Quando a abolição da escravidão foi realizada, houve um choque no patriciado rural, uma vez que seu prestígio foi transferido para um outro grupo social. Tal fato, somado à cultura da personalidade, implicou na valorização das profissões liberais, engendrando fenômenos como o bacharelismo. Estas profissões foram visadas em razão da representação finalística do que nelas é feito, ou seja, ao ingressar nelas, os fidalgos buscavam o trabalho como um fim em si mesmo e não na obra dele adveniente.

Holanda aponta que este era um dos fatores pelos quais a intelectualidade brasileira tendia a produzir seu conhecimento sem a necessária análise das dinâmicas sociais, o que lhes imprime um caráter livresco e artificioso. Assim, parte da intelectualidade que cultuava a literatura francesa havia se qualificado como polo perpetuador do conservadorismo, acreditando que o talento é algo inato, não sendo preciso estudar para adquiri-lo, e que o alheamento em relação ao mundo é necessário para entender o próprio mundo. Por isso, os membros deste grupo social valorizavam teorias somente pela sua dificuldade, construindo interpretações meramente retóricas acerca da realidade social.

Aos fatores acima somou-se a preponderância do latifúndio, que minou qualquer possibilidade de se constituir na América Portuguesa uma organização para outra atividade que não a lavoura. Isto se justificava porque na grande fazenda produzia-se e reproduziase, fazendo com que não fossem necessários outros ofícios que representassem uma verdadeira empresa capitalista. Tendo isso em vista isto,

o peculiar da vida brasileira parece ter sido, por essa época, uma acentuação enérgica do afetivo, do irracional, do passional, e uma estagnação ou antes uma atrofia correspondentes das qualidades ordenadoras, disciplinadoras, racionalizadoras. Quer dizer, exatamente o contrário do que parece convir a uma população sem via de originar-se polidamente (HOLANDA, 2014, p. 71). 
A racionalização da vida se constitui como uma virtude lucrativa, mas ela, assim como a despersonalização, foi afastada pela estirpe ibérica quando as ações afetivas e tradicionais se sobressaíram. Destarte, mesmo nas relações comerciais, que são tipicamente impessoais, o fato de haver laços diretos facilitava a congregação de um negócio, de modo que o freguês assume a posição de amigo. Esta negação da racionalidade em prol do personalismo e da afetividade é um traço marcante do arcabouço cultural ibérico, incapaz de proporcionar relações impessoais e mecânicas, que estão no cerne do capitalismo ocidental.

\section{$4 \quad$ O CORDIALISMO E AS INSTITUIÇÕES POLÍTICAS DO BRASIL}

Um dos tipos criados por Holanda é o homem cordial, que caracteriza um modus vivendi específico dos brasileiros. Ao contrário das tendências apontadas por Weber (2016, p. 685-686), o homem cordial se erige sobre relaçóes afetivas e tradicionais em detrimento das racionais. Assim, para construir este tipo, Holanda admitiu, tal como fez Weber, que entre a família e o Estado Moderno havia uma descontinuidade, no sentido de os laços afetivos presentes na primeira serem sucumbidos pelas relaçóes impessoais do segundo. Com isso, se erigia uma igualdade formal destituída dos laços afetivos, de modo que, nas palavras do teórico alemão:

\footnotetext{
Somente a burocratização do Estado e do direito vê, em geral, também a possibilidade definitiva de uma rigorosa distinção conceitual entre uma ordem jurídica "objetiva" e os direitos "subjetivos" do indivíduo, por ela garantidos, do mesmo modo que a distinção entre o direito "público", referente às relaçôes das autoridades entre si e com os "súditos", e o direito "privado", que regula as relações entre os indivíduos dominados. Esta pressupõe a distinção conceitual entre o "Estado", como portador abstrato de direitos senhoriais e criador de "normas jurídicas" e todas as "autorizaçôes" pessoais dos indivíduos - ideias que, nesta forma, tinham que ser alheias à natureza da estrutura de dominação pré-burocrática, especialmente a patrimonial e a feudal (WEBER, 2004, p. 230).
}

Destarte, a fim de qualificar o homem cordial, Holanda aponta que a crise que seguiu esta transição no Brasil gerou dificuldades pela oposição à abolição da velha ordem, pois os laços afetivos passaram a ser substituídos por relaçốes impessoais calcadas em virtudes antifamiliares. Neste contexto, subsistiram algumas famílias retardatárias, ou seja, defensoras da velha ordem, educando seus filhos para constituir relações no âmbito doméstico. Neste âmbi- 
to o sentido das ações dos agentes sociais ganha traços afetivos (sentimentos em gerais, da mais pura pena à mais ardilosa raiva) e tradicionais.

No Brasil, as relaçôes da esfera doméstica se difundiram para as demais, fornecendo sentidos para ações de outros agentes sociais. Em razão disso, na administração pública, por exemplo, o caráter burocrático foi sucumbido pelo patrimonial. Neste sentido, aqueles que se apropriavam dos cargos administrativos tendiam a tratar dos negócios públicos como se fossem de seu interesse pessoal, não distinguindo entre as esferas pública e privada. Ao mencionar o caráter patrimonial, Holanda remete novamente às consideraçóes de Weber, para quem

[...] o complexo político patrimonial, modificado em sentido prebendal e feudal, em oposição ao sistema de "autoridades" regulamentadas de forma geral por ordens objetivas e com deveres administrativos circunscritos e igualmente regulamentados, constitui, em resumo, um cosmo ou, dependendo do caso, um caos de direitos de usufruto hereditários e deveres subjetivos, concretamente definidos, do senhor, dos detentores de cargos e dos dominados, que se cruzam e se restringem mutuamente e de cuja combinação nasce uma ação social impossível de construir com modernas categorias do direito público e à qual a denominação "Estado", no sentido atual da palavra. Se aplica menos ainda do que aos complexos políticos puramente patrimoniais (WEBER, 2004, p. 302).

Tal indistinção entre o público e o privado constitui uma das formas em que se manifesta o "fundo emotivo extremamente rico e transbordante" (HOLANDA, 2014, p. 172) do brasileiro, que age de forma cordial. Por isso, o homem cordial trata de forma hospedeira e generosa, familiar, aqueles que o interessam, perpetuando a orientação das ações pelos sentidos construídos no meio rural e patriarcal. Este tratamento cordial não deve ser confundido com boas maneiras, com civilidade ${ }^{4}$. Antes de tudo, o uso da polidez serve apenas como uma máscara nas relações sociais para estabelecer a intimidade presente nas relaçóes familiares.

Relacionando as consideraçóes de Holanda com as de Weber, é possível inferir que as características do homem cordial se ligam ao tipo de dominação tradicional. A dominação tradicional tem como características a crença no tradicionalismo sagrado, ou seja, no monopólio de bens simbólicos e materiais que determinam posições sociais, de modo que

4 Ao comentar as distinções entre as edições de 1936 e 1948, Feldman (2013, p. 120-125) aponta que, nesta última, Holanda se empenhou para desfazer a confusão interpretativa do termo "cordialidade", que na primeira havia sido colocado de modo a permitir que fosse entendido como "bondade". 
as relaçôes sociais e gerais são reguladas pela tradição, pelos privilégios, pelas relaçôes de fidelidade feudais ou "patrimoniais", pela honra estamental e pela "boa vontade". O poder senhorial acha-se, pois, repartido entre o senhor e o quadro administrativo com título de propriedade de privilégio, e esta divisão de poderes estamental imprime um caráter altamente estereotipado ao tipo de administração (WEBER, 2016, p. 548).

Este tipo de dominação está no cerne da dificuldade de a democracia se enraizar no Brasil. Por isso, o liberalismo democrático jamais se assentou em solo brasileiro, tendo em vista que ele exige uma atitude impessoal, contrária à essência das ações afetivas e tradicionais perpetuadas no país. Somente em parte a ideia liberal foi assimilada: a negação de uma "autoridade incômoda", que não permite tratar os governantes com familiaridade, tornando a democracia um "lamentável mal-entendido" (HOLANDA, 2014, p. 192).

Holanda então assevera que, no âmbito político, a preponderância do elemento afetivo (emotivo) sobre o racional é evidente, de modo que a ausência de partidos verdadeiros se dá em razão da inadaptação ao impessoalismo da democracia. "Democracia”, portanto, aparecia como um conceito puramente ornamental, pois aquilo que vigorava fortemente no Brasil era o personalismo, herança da cultura ibérica. Como supramencionado, se na primeira edição o personalismo foi colocado como uma solução para os problemas da política brasileira, a partir da segunda, embora reconhecendo sua predominância, Holanda o trata como um obstáculo a ser vencido para que o regime verdadeiramente democrático pudesse se erigir.

\section{A DESINTEGRAÇÃO DAS RAÍZES IBÉRICAS}

Ao mencionar a revolução gradual, Holanda a relaciona com o fim do predomínio agrário no Brasil a partir da abolição da escravatura, tendo como tendência a eliminação das raízes ibéricas, que acontecerá quando brotarem as raízes do americanismo. A abolição é considerada um divisor de águas em Raizes do Brasil, sinalizando a crise do legado colonial, um momento visível das transformaçóes dos novos tempos. Com ela acontecem eventos como a dinamização da economia monetária, a crescente despersonalização das relações de trabalho, os novos modelos de família e a afirmação da competição como valor social. Tudo isto tenciona a cordialidade e possui virtudes antifamiliares, atributos precípuos das raízes ibéricas.

Importante mencionar que, antes de tratar das cidades como móvel da revolução gradual, Holanda já havia tocado no assunto ao tratar dos primórdios da colonização. Com 
base na metodologia histórico-comparativa e tipológica, Holanda distinguiu os castelhanos dos portugueses em dois tipos: o ladrilhador e o semeador. Esta distinção foi feita com uma remissão direta a Weber, salientando a importância que tal autor dá para as cidades como instrumento de dominação.

Do ponto de vista sociológico, a cidade é um povoado extenso que implica na falta de conhecimento pessoal e mútuo entre seus habitantes, esfacelando os laços afetivos. Esta realização pôde ser observada na colonização espanhola, que tratou de traçar planos urbanísticos, sendo este o motivo pelo qual se caracterizam como ladrilhadores. Estes planos estavam juridicamente previstos na Lei das Índias, para a formação de núcleos de povoação estáveis, sobre os quais pesaram, posteriormente, as mãos fortes do Estado.

O contrário aconteceu com a colonização portuguesa, que tratou mais de feitorizar seus empreendimentos do que traçá-los metodicamente. Isto implicou no predomínio rural até a abolição da escravatura como supramencionado, sendo, por isso, semeadores. Salientase que, somente a partir do século XVIII, com o descobrimento de ouro nas Minas Gerais, se deu uma interiorização do território e que despertou em Portugal um senso para ordenar a colônia. Esta organização foi feita mediante uma série de imposiçôes institucionais de demarcação e regulação do fluxo de pessoas, mas ainda foi restrita.

Comparando a colonização espanhola com a portuguesa, Holanda conclui que duas lógicas distintas predominaram, respectivamente, em cada uma delas: a do ladrilhador e a do semeador. A primeira lógica está ligada à noção de planejamento, adveniente do tino centralizador de Castela, que lida com a aglutinação de povos desunidos, tendo que impor uma forte padronização para a manutenção da coesão social sob constante ameaça de desagregação. A segunda lógica, por seu turno, se relaciona à liberdade e ao desleixo, permitidos pelo fato de em Portugal, por sua longeva unidade política, ter se constituído certa homogeneidade étnica, criando laços sociais que imprimiram nas práticas reproduzidas uma força de coesão e um sentido espiritual para a aquisição de riquezas.

Malgrado a tentativa de ordenação nas Minas Gerais, foi somente com a migração da família real que mudanças começaram a ser apontadas, sobretudo em razão do aumento da infraestrutura urbana, mas foram minadas pelo apego a traços pessoais e instintivos. Destarte, com a fundação de cursos superiores em 1827, aqueles que neles adentraram, passaram por um processo de readaptação, pois tais cursos possuíam um viés particularista que se opunha aos valores familiares aprendidos na vida doméstica. Foi por isso que o início da urbanização no Brasil causou uma série de desequilíbrios sociais, tendo em vista sua tendência contrária ao império da família patriarcal. 
Sobre esse aspecto, Weber, a tratar da cidade no Ocidente, havia apontado situações análogas às de Holanda. Para ele, a cidade, cujo elemento distintivo era o mercado estabilizado, foi se transformando em uma corporação territorial autocéfala, com órgãos judiciais e administrativos próprios estabelecidos conforme a ordem nela vigente, implicando em um processo de gradual burocratização, de "impessoalização", tratado na seção anterior.

Tendo como escopo as asserçôes weberianas, Holanda aponta que a infraestrutura construída, como o sistema de linhas férreas e o de comunicaçóes, aumentou a interdependência entre campo e cidade. Aos poucos, isto faria com que as zonas agrícolas deixassem de parecer baronias para se assemelharem a um centro industrial. Todavia, subsistiria ainda uma consciência coletiva com raízes imperiais, que só seria eliminada com o enraizamento do americanismo em um processo de revolução gradual.

\section{CONCLUSÃO}

Feita a aproximação da obra de Weber à de Holanda, convém responder à questão acerca daquilo que ele trouxe na bagagem quando retornou da Alemanha. Apesar de ter realizado uma passagem rápida pelas terras germânicas, entre os anos de 1929 e 1930, Holanda conseguiu extrair dos autores alemães recursos metodológicos e substanciais, trazendo-os, adaptando-os e aplicando-os em seu trabalho de interpretação do Brasil.

Para Weber (2016, p. 151), a interpretação é uma categoria que pode ser entendida como o incitamento para uma avaliação ou para um juízo, configurando-se como um conhecimento interpretativo causal neste último caso. No entendimento, a compreensão se apresenta como posicionamento frente ao sentido objetivo de um juízo, mas ela não se dá somente em casos de conhecimento objetivo. Ademais, salienta-se que a interpretação somente acontece quando há interpretabilidade, ou seja, quando há sentido na ação capaz de ser apreendido.

Tendo isto em vista, Holanda buscou o sentido das ações que auxiliaram na fixação das raizes do Brasil. Estas ações foram tratadas como realizadas por indivíduos históricos, ou seja, conglomerados de agentes aglutinados em uma única formação social, influenciada pelas e capaz de influenciar as formações socioculturais. Salienta-se que a presença do caráter social, em Raizes do Brasil, foi essencial para a inovação analítica da obra, sendo possível notar que Holanda adotou a posição weberiana a respeito de a particularidade do conhecimento histórico se destoar do mecanicismo naturalista. 
As Raizes weberianas de uma interpretação do Brasil

Enfim, a bagagem intelectual de Holanda retornou cheia ao Brasil! Nela, ele trouxe tanto a metodologia weberiana, como aqui exposto, quanto abordagens de outros autores, como apontam interpretações supracitadas. Portanto, revisitar sua obra possibilita a apreensão de traços metodológicos desenvolvidos em outros países, mas adaptados à interpretação da realidade brasileira. A metodologia weberiana, particularmente, por lidar com o sentido das açôes, colocando-as em um plano histórico, constitui uma importante chave teórica para a realização de análises sociais, como a realizada em Raizes do Brasil. 


\section{REFERÊNCIAS BIBLIOGRÁFICAS}

ALBERT, G. Holismo metodológico moderado: uma interpretação weberiana do modelo macro-micro-macro. Politica E'Sociedade, v. 15, n. 34, p. 43-76, 2016.

CANDIDO, A. Sérgio em Berlim e depois. Novos Estudos CEBRAP, v. 2, n. 3, p. 4-9, 1982.

CANDIDO, A. A revolução de 1930 e a cultura. Novos Estudos CEBRAP, v. 2, n. 4, p. 27-35, 1984.

CANDIDO, A. O significado de Raízes do Brasil. In: HOLANDA, S. B. de. Raizes do Brasil. 27. ed. São Paulo: Companhia das Letras, 2014, p. 9-24.

CONH, G. O Pensador do Desterro. Folha de São Paulo, 23 jun. 2002. Disponível em: https://www1.folha.uol.com.br/fsp/mais/fs2306200207.htm. Acesso em: 16 jan. 2020.

BASTOS, E. R. Um livro entre duas constituintes. In: HOLANDA, S. B. de. Raizes do Brasil. Edição Crítica. São Paulo: Companhia das Letras, 2016. E-book.

EUGÊNIO, J. K. Um ritmo espontâneo: o organicismo em Raízes do Brasil e Caminhos e Fronteiras, de Sérgio Buarque de Holanda. Tese (Doutorado em História). Universidade Federal Fluminense, Rio de Janeiro, 2011.

FELDMAN, L. Um clássico por amadurecimento: Raízes do Brasil. Revista Brasileira de Ciências Sociais, v. 28, n. 82, p. 119-140, 2013.

HOLANDA, S. B de. Raízes do Brasil. 27. ed. São Paulo: Companhia das Letras, 2014

MATA, S. Tentativas de desmitologia: a revolução conservadora em Raízes do Brasil. Revista Brasileira de História, v. 36, n. 73, p. 63-87, 2016.

MONTEIRO, P. M. A queda do aventureiro: aventura, cordialidade e os novos tempos em Raízes do Brasil. Dissertação (Mestrado em Sociologia). Universidade Estadual de Campinas, Campinas, 1996. 
As Raizes weberianas de uma interpretação do Brasil

SELL, C. E. Max Weber e o átomo da sociologia. Civitas - Revista de Ciências Sociais, v. 16, n. 2,2016

VIANNA, L. W. Weber e a interpretação do Brasil. Novos Estudos, v. 53, p. 33-47, 1999.

WAIZBORT, L. O mal-entendido da democracia: Sérgio Buarque de Holanda. Raízes do Brasil, 1936. Revista Brasileira de Ciências Sociais, v. 26, n. 76, p. 39-62, 2011.

WEBER, M. Economia e Sociedade. Fundamentos da sociologia compreensiva. 3. ed. Brasília: Editora da Universidade de Brasília, 2000.

WEBER, M. Economia e Sociedade. Fundamentos da sociologia compreensiva. v. 2. 3. ed. Brasília: Editora da Universidade de Brasília, 2004.

WEBER, M. A ética protestante e o espirito do capitalismo. São Paulo: Martin Claret, 2013.

WEBER, M. Metodologia das ciências sociais. 5. ed. São Paulo: Cortez; Campinas, SP: Editora da Unicamp, 2016. 